\title{
Mononuclear cells modulate the activity of pancreatic stellate cells which in turn promote fibrosis and inflammation in chronic pancreatitis
}

\author{
Christoph W Michalski*†1,2, Andre Gorbachevski ${ }^{\dagger 2}$, Mert Erkan ${ }^{\dagger 1}$, \\ Carolin Reiser ${ }^{1}$, Stefanie Deucker ${ }^{2}$, Frank Bergmann ${ }^{3}$, Thomas Giese ${ }^{4}$, \\ Markus Weigand ${ }^{5}$, Nathalia A Giese ${ }^{2}$, Helmut Friess ${ }^{1}$ and Jörg Kleeff ${ }^{1}$
}

\begin{abstract}
Address: ${ }^{1}$ Department of Surgery, Technische Universität München, Munich, Germany, ${ }^{2}$ Department of General Surgery, University of Heidelberg, Germany, ${ }^{3}$ Institute of Pathology, University of Heidelberg, Germany, ${ }^{4}$ Institute of Immunology, University of Heidelberg, Germany and ${ }^{5}$ Department of Anaesthesiology, University of Heidelberg, Germany

Email: Christoph W Michalski* - christoph.michalski@gmx.de; Andre Gorbachevski - gorbik@gmx.de; Mert Erkan - mert.erkan@gmx.de; Carolin Reiser - carolin.reiser@gmx.de; Stefanie Deucker - stdeucker@gmx.de; Frank Bergmann - frank.bergmann@med.uni-heidelberg.de; Thomas Giese - thomas.giese@urz.uni-heidelberg.de; Markus Weigand - markus.weigand@med.uni-heidelberg.de;

Nathalia A Giese - nathalia.giese@med.uni-heidelberg.de; Helmut Friess - helmut.friess@chir.med.tu-muenchen.de; Jörg Kleeff - kleeff@gmx.de

* Corresponding author †Equal contributors
\end{abstract}

Journal of Translational Medicine 2007, 5:63 doi:10.1 186/1479-5876-5-63

Accepted: 5 December 2007

This article is available from: http://www.translational-medicine.com/content/5/I/63

(c) 2007 Michalski et al; licensee BioMed Central Ltd.

This is an Open Access article distributed under the terms of the Creative Commons Attribution License (http://creativecommons.org/licenses/by/2.0), which permits unrestricted use, distribution, and reproduction in any medium, provided the original work is properly cited.

\begin{abstract}
Background: Interactions between mononuclear cells and activated pancreatic myofibroblasts (pancreatic stellate cells; PSC) may contribute to inflammation and fibrosis in chronic pancreatitis (CP).

Methods: Markers of fibrosis and inflammation were concomitantly analysed by immunohistochemistry in chronic pancreatitis tissues. In vitro, PSC were stimulated with TNFalpha and LPS. Primary human blood mononuclear cells (PBMC) and PSC were cocultured, followed by analysis of cytokines and extracellular matrix (ECM) proteins. PBMC were derived from healthy donors and CP and septic shock patients.
\end{abstract}

Results: In areas of mononuclear cell infiltration in chronic pancreatitis tissues, there was decreased immunoreactivity for collagen I and fibronectin, in contrast to areas with sparse mononuclear cells, although PSC were detectable in both areas. LPS and TNFalpha induced collagen I and fibronectin levels as well as the matrix degradation enzyme MMP-I. Coculture experiments with PSC and PBMC revealed increased fibronectin secretion induced by PBMC. In addition, donor and CP PBMC significantly induced an increase in IL-6, MCP-I and TGFbeta levels under coculture conditions. Determination of the source of cytokines and ECM proteins by mRNA expression analysis confirmed PSC as major contributors of ECM production. The increase in cytokine expression was PBMC- and also PSC-derived.

Conclusion: Mononuclear cells modulate the activity of pancreatic stellate cells, which may in turn promote fibrosis and inflammation. 


\section{Background}

The exact pathogenesis of chronic pancreatitis (CP) is unknown, but the disease results from an injury to a pancreatic cell population, which then activates pancreatic stellate cells (PSC) as a final common response. This process is associated with excessive accumulation of extracellular matrix (ECM) proteins by PSC and a massive infiltration of mononuclear cells [1-6]. Clinically, CP is accompanied by a severe pain syndrome and by a loss of pancreatic function (both exocrine and endocrine). PSC have been determined as the major source of ECM protein production, and have also been shown to produce cytokines and chemokines [7-11]. Thus, anti-fibrogenic therapies aim to reduce the activity of PSC in order to inhibit the accumulation of ECM proteins and also to prevent digestion of the basement membranes, which allows PSC to enter inflammatory areas and to excessively deposit ECM.

In liver cirrhosis, tissue macrophages derived from blood mononuclear cells have been shown to influence fibrogenesis by activating hepatic myofibroblasts [12], while suppression of macrophage infiltration inhibits hepatic stellate cell activation and thus liver fibrogenesis. During fibrogenesis, local inflammation may not be initiated by apoptosis/necrosis of parenchymal cells but by resident and recruited inflammatory cells; these inflammatory cells, once in an active state, release cytokines which in turn activate stellate cells $[13,14]$.

Recent studies have investigated the response of hepatic stellate cells to lymphocyte subsets, which can be divided into Th1 and Th2 predominant [15]. Different Th1 or Th2 subsets seem to modulate the fibrotic response towards anti- or pro-fibrogenesis, thus resulting in an apparent IL10 paradox: IL-10 is anti-fibrogenic but is produced during a pro-fibrotic Th2 immune response [16]. Mononuclear cells within fibrotic areas have been shown to secrete a wide variety of agents which induce matrix generation/ degradation [17-19], but there are no data on different responses of PSC to PBMC from various sources - i.e., healthy donors and CP patients.

In $\mathrm{CP}$, a generalized immune response has been suggested due to increased expression of TNFalpha and its receptor on PBMC and which was associated with PSC cytotoxicity [20]. Furthermore, it has been shown that LPS-activated macrophages stimulate the synthesis of ECM proteins by PSC [21]. In rats, suppression of macrophage infiltration inhibited activation of hepatic stellate cells [12]. Similarly, it has been shown that both pro- and anti-inflammatory cytokines, such as PDGF and TGFbeta, activate PSC and thus contribute to pancreatic fibrogenesis [22]. TGFbeta was subsequently confirmed as a key regulator of ECM production and PSC proliferation due to its inhibi- tion of MMPs in an autocrine fashion which enhanced fibrogenesis by reducing collagen degradation [23].

In terms of transcriptional regulation, nuclear factor kap$\mathrm{paB}(\mathrm{NFkB})$ is a well-characterized transcription factor which is activated by oxidative stress or by TNFalpha, and which activates key anti-fibrotic genes such as MMP-2. Interestingly, inhibition of NFkB by IkB has been shown to decrease IL-6 and ICAM-1 levels in rat hepatic stellate cells during experimental liver injury [24]. Thus in many ways, lymphocytes modulate fibrogenesis depending on their activation state, either towards anti- or pro-fibrosis. Clinically, it is hypothesized that immune suppression accelerates the development and progression of fibrosis, underlining the importance of immune regulation for stellate cell function [25-27].

Understanding the pathobiological mechanisms underlying activation states of immune cells and PSC, as well as their interactions which are associated with the development of chronic pancreatitis, is therefore a prerequisite for the design of novel therapeutic approaches. Here, we demonstrate the significance of an interaction between PBMC and PSC which influences fibrogenesis and inflammation in chronic pancreatitis.

\section{Patients, Materials and Methods \\ Patients and tissue sampling}

Patients with chronic pancreatitis $(\mathrm{n}=13)$, patients with sepsis $(n=4)$, and age- and sex-matched healthy adults ( $n$ $=10$ ) were eligible for enrollment in the study. Blood samples were collected preoperatively from CP patients or on the intensive care unit from septic shock patients. Tissue samples were collected during pancreatic resections for CP. These were either immediately processed for isolation of primary human pancreatic stellate cells or snap frozen at $-80^{\circ} \mathrm{C}$ or formalin fixed and paraffin embedded. The use of human material for analysis was approved by the local ethics committee (University of Heidelberg, Germany), and written informed consent was obtained prior to the operation and the blood sampling.

\section{Immunohistochemistry}

Immunohistochemistry was performed as described previously $[28,29]$. Briefly, consecutive sections from chronic pancreatitis patients $(\mathrm{n}=10)$ were stained for collagen 1 , fibronectin, alpha-SMA, CD31, CD45 and vimentin. Primary antibodies against collagen1 (diluted 1:600; ab6308, Abcam, Cambridge, UK), fibronectin (diluted 1:500; F3648, Sigma Aldrich, Taufkirchen, Germany), alpha-SMA (diluted 1:500; M0851, DAKO Cytomation, Hamburg, Germany), CD-31 (diluted 1:50; M0823, DAKO Cytomation), CD45 (ready to use; N1514, clone 2B11\&PD7/26, DAKO Cytomation) and vimentin (diluted 1:500; M7020, DAKO Cytomation) were applied 
at $4{ }^{\circ} \mathrm{C}$ overnight. Secondary antibodies (anti-mouse) for collagen1, alpha-SMA, CD31, CD45, and vimentin and (anti-rabbit) for fibronectin were purchased from DAKO Cytomation as EnVision+ ready-to-use solutions.

\section{Human primary PSC and PBMC isolation and culture}

Human PSC isolation and culture were performed as described previously $[8,28]$. PBMC were isolated from heparinized blood by ficoll density gradient separation (Histopaque $^{\circledR}-1077$, Sigma-Aldrich, Taufkirchen, Germany) as previously described [30].

\section{Treatment of PSC with TNF-alpha and LPS}

Sister clones of PSC were treated with TGFbeta $1(5 \mathrm{ng} / \mathrm{ml}$, GF111 Chemicon Temecula, CA, USA), TNFalpha (1 ng/ ml, GF023 Chemicon Temecula, CA, USA), and LPS (1 $\mathrm{ng} / \mathrm{ml})$. Collection of RNA was performed at 6 and 24 hours as described before [31].

\section{Coculture of PSC and PBMC}

Primary human PSC were cocultured with freshly isolated PBMC using cell culture inserts with $1.0 \mu \mathrm{m}$ pore size according to the manufacturer's instructions (BD Falcon, city, NJ, USA). PSC were plated on the bottom of 6-well cell culture plates at a density of $25,000 / \mathrm{cm}^{2}$ in $3 \mathrm{ml}$ of DMEM/Ham's F12 in the presence of 10\% FCS 24 hours prior to the onset of coculture. Thereafter, medium was changed to DMEM/Ham's F12 with $0.5 \%$ FCS and freshly isolated human PBMCs were seeded on the membrane insert in $2 \mathrm{ml}$ of the same culture medium. The ratio of PBMC/PSC was 15:1. After overnight incubation (24 hours), the supernatants from PSC and PBMC were mixed and immediately frozen at $-80^{\circ} \mathrm{C}$ for ELISA experiments; the cells were processed and frozen at $-80^{\circ} \mathrm{C}$ prior to analysis by QRT-PCR and immunoblotting.

\section{Quantitative real-time RT-PCR}

All reagents and equipment for $\mathrm{mRNA} / \mathrm{cDNA}$ preparation were purchased from Roche Applied Science Diagnostics (Mannheim, Germany). QRT-PCR was performed as described previously [31]. All primers were obtained from Search-LC (Heidelberg, Germany).

\section{Immunoblot analysis}

For immunoblot analyses of cocultured PSC and PBMC as well as LPS- or TNFalpha-treated PSC, cells were processed as described [28,29]. Primary antibodies against collagen type-1 (diluted 1:2000; sc-28657, Santa Cruz Biotechnology, Santa Cruz, CA, USA), fibronectin (1:10,000; F3648, Sigma Aldrich, Taufkirchen, Germany), alphaSMA (1:10,000; M0851, DAKO Cytomation, Hamburg, Germany) and gamma-tubulin as an equal loading control (1:5,000; sc-7396, Santa Cruz Biotechnology) were applied overnight at $4{ }^{\circ} \mathrm{C}$; secondary antibodies (collagen type-1 diluted 1:2,000; fibronectin, alphaSMA and gamma-tubulin diluted 1:5,000) were added for one hour at room temperature. Densitometry was performed as described previously [28].

\section{Enzyme-Linked Immunosorbent Assay (ELISA)}

To determine levels of MCP-1, IL-6 and TGFbeta in coculture supernatants, commercial ELISA kits were used according to the manufacturer's instructions (OptEIA $^{\text {тм }}$ ELISA kits for human MCP-1 and IL-6 from BD Biosciences [BD, Heidelberg, Germany]; ELISA DuoSet ${ }^{\circledast}$ human TGFbeta kit from R\&D Systems [R\&D, Abingdon, UK]).

\section{Nuclear extracts and NFkB p65 ELISA}

To isolate the nuclear protein fraction and to measure nuclear NFkB p 65 levels, cells were processed after 2 hours of coculture using a commercial TransAM ${ }^{\mathrm{TM}}$ NF-kB family ELISA-based kit according to the manufacturer's instructions (Active Motif, Rixensart, Belgium).

\section{Statistical analysis}

Statistical analysis was performed using GraphPad Prism 4 Software (GraphPad, San Diego, CA, USA). A paired ttest was used for analysis of densitometries. The MannWhitney U test was used for comparisons of cytokine levels in cell culture supernatants and for comparisons of cytokine expression in PBMC. Analysis of variance (Kruskal-Wallis test) was performed for comparisons of differences of PSC mRNA expression levels, followed by a post-hoc Dunn's multiple comparison test. The level of statistical significance was set at $\mathrm{p}<0.05$.

\section{Results}

Suppression of ECM production in mononuclear cell infiltrates in chronic pancreatitis

To judge the pattern of extracellular matrix protein distribution within and in the vicinity of mononuclear cell infiltrates in human chronic pancreatitis tissues $(n=10)$, immunohistochemistry was performed with antibodies against mononuclear cells (CD45; MNC), activated pancreatic stellate cells (alpha smooth muscle actin, alphaSMA; vimentin; activated PSC), and the ECM proteins fibronectin and collagen 1 . To distinguish between PSC and small vessels, the endothelial marker CD31 was used. We then analysed patterns of stellate cells, mononuclear cells and matrix deposition. Pancreatic stellate cell activity (alpha-SMA-positive and vimentin-positive cells: Figure 1A \&1B; for endothelial staining see Figure 1C) and matrix deposition were different around different patterns of mononuclear cell infiltration, namely, around and within 1) clusters (Figure 1D; arrows), 2) loosely distributed mononuclear cells (Figure 1D; arrowhead) and 3) single mononuclear cells (Figure 1A-C; arrowheads; PSC: alphaSMA-positive and vimentin-positive, but CD31-negative). Activated PSC deposit extracellular matrix (ECM; 

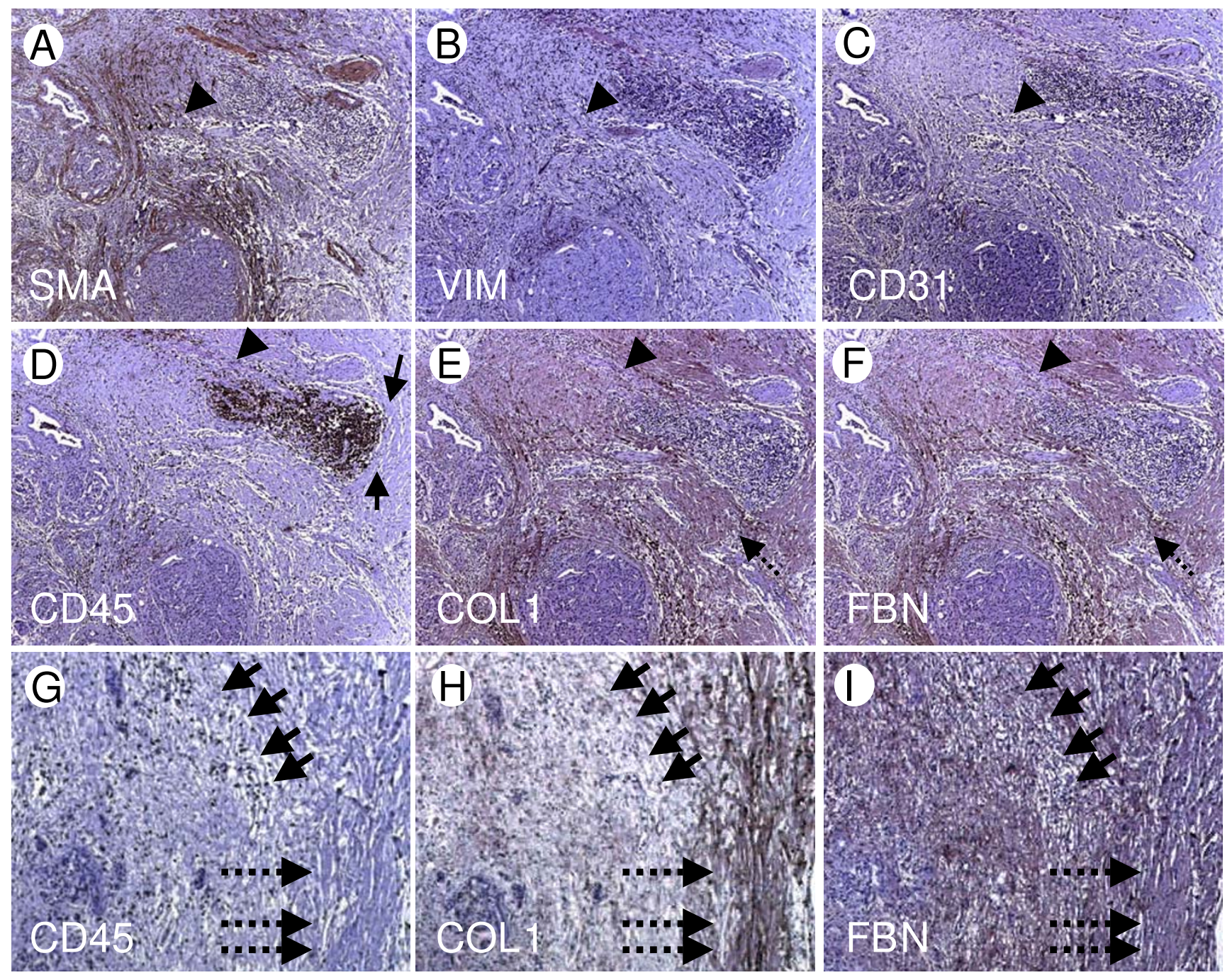

Figure I

Immunohistochemistry of human chronic pancreatitis tissue specimens. Consecutive sections of chronic pancreatitis tissues were subjected to immunohistochemistry using antibodies against alphaSMA (A; SMA), vimentin (B; VIM), CD3I (C), CD45 (D), collagen I $(E ; C O L)$ and fibronectin (F; FBN). Arrows: area around packed clusters of mononuclear cells. Arrowheads in A-C: pancreatic stellate cells (SMA- and VIM-positive, CD3I-negative). Arrowhead in D: loosely distributed area of mononuclear cell infiltration. Arrowhead in E\&F: areas of less intense immunoreactivities for collagen I and fibronectin. Dotted arrows: Areas of strong collagen I and fibronectin staining. Original magnification: $\times 50$. (G) Arrows: areas of loosely distributed/single mononuclear cells, dotted arrows: area without mononuclear cells. (H\&l) Arrows/dotted arrows: corresponding areas to $(G)$.

Figure 1D, arrows; Figure 1E \&1F, dotted arrows) and as expected, PSC are found mainly in areas of inflammation and ECM deposition (Figure 1A \&1B; for endothelial staining see Figure 1C). Activated PSC were also found within clusters of mononuclear cells (Figure 2A \&2D, arrows; Figure 2B \&2C, corresponding vimentin and CD31 stainings) and, therefore, one might expect deposition of ECM within these clusters but none is seen (Figure $2 \mathrm{E} \& 2 \mathrm{~F}$, arrows) suggesting mononuclear cell suppression. These findings are corroborated by further immuno- histochemistries showing that in areas of loosely distributed/single mononuclear cells (Figure 1G, arrows), there is only faint collagen 1 and fibronectin staining (Figure $1 \mathrm{H} \& 1 \mathrm{I}$, arrows). However, in areas without mononuclear cells (Figure 1G, dotted arrows), there is strong ECM protein staining (Figure $1 \mathrm{H} \& 1 \mathrm{I}$, dotted arrows).

\section{LPS and TNFalpha modulate PSC activity}

The effects of pro-inflammatory substances on the activation state of PSC were examined by incubation with 

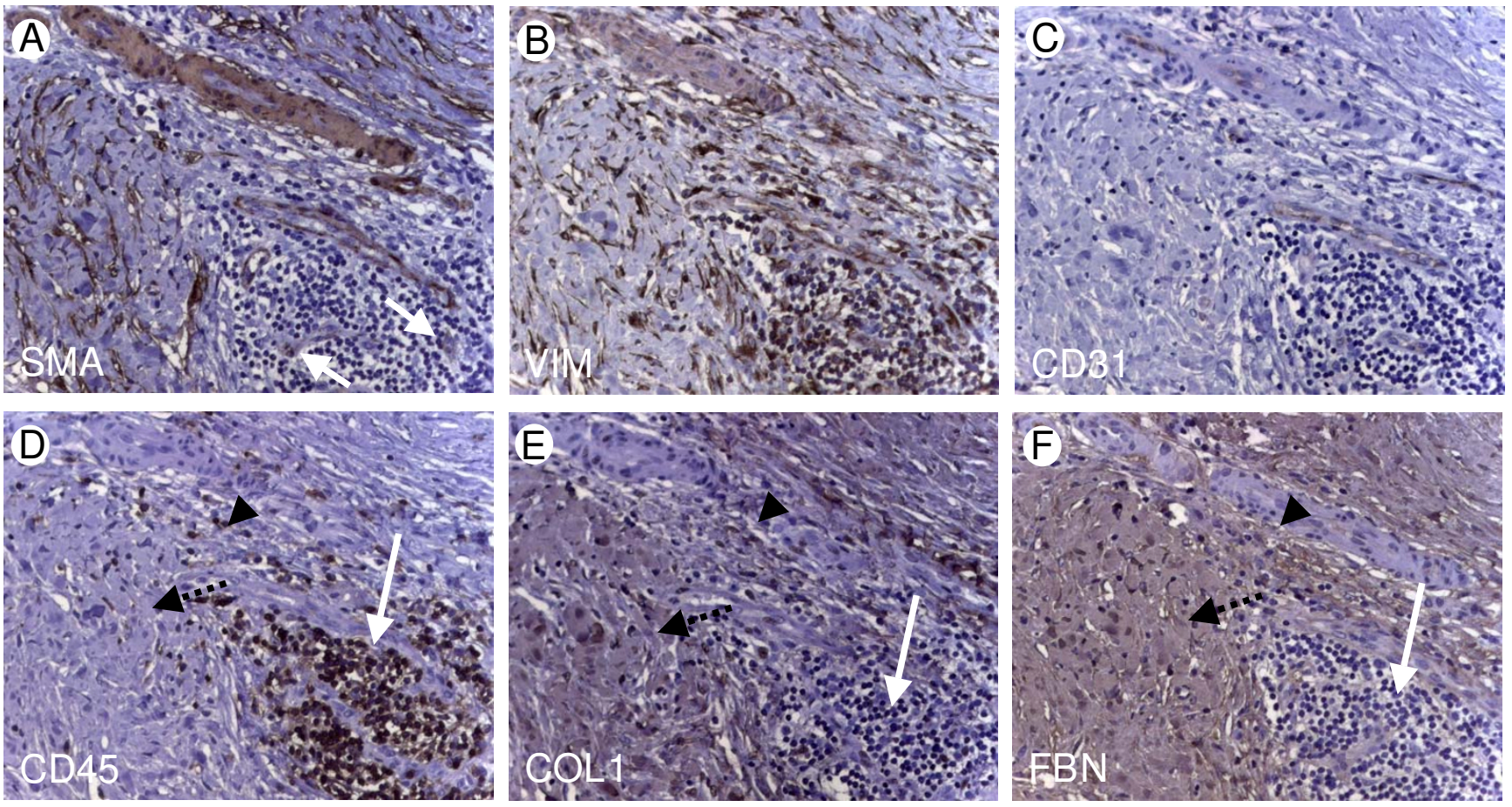

Figure 2

Details of immunohistochemical analysis of chronic pancreatitis tissues. (A\&B) Pancreatic stellate cells are seen within clusters of mononuclear cell infiltration. (A) Arrows: stellate cells. (C) To exclude that alphaSMA- (SMA) and vimentinpositive (VIM) structures are endothelia, CD3I staining was performed. (D-F) In areas of loosely packed mononuclear cells (arrowhead in D) and packed mononuclear cells (white arrow in D), there is sparse immunoreactivity for collagen I (arrowhead and white arrow in E) and moderate staining for fibronectin (arrowhead and white arrow in F). In areas with a low number of CD45-positive mononuclear cells (dotted arrow in D), the staining intensities for collagen I (dotted arrow in E; $\mathrm{COL}$ ) and fibronectin (dotted arrow in F; FBN) are stronger. Original magnification: $\times 200$.

TNFalpha and lipopolysaccharide (LPS). As shown before [28], analysis of "functional" ECM proteins can be performed on cell culture supernatants. This revealed that TNFalpha and LPS exerted similar effects on PSC. Immunoblot analysis of cell culture supernatants was used to analyze the secretion of the extracellular matrix proteins collagen 1 and fibronectin by PSC. These experiments showed that both LPS and TNFalpha increased the secretion of collagen 1 and fibronectin (Figure 3A). Furthermore, the matrix degradation enzyme MMP-1 was induced (LPS by $46 \%$; TNFalpha by $454 \%$ ), while its inhibitor TIMP-2 was suppressed (by $20 \%$ and $18 \%$, respectively; data not shown). Densitometry adjusted to control PSC supernatants revealed that LPS increased collagen secretion (Figure 3A, p < 0.001) and induced a trend towards increased fibronectin levels (Figure 3A). TNFalpha induced an increase in collagen $1(\mathrm{p}=0.069)$ and an increase in fibronectin levels ( $p=0.007)$.

\section{In vitro increase of ECM production is induced by PBMC}

To evaluate whether mononuclear cells alter ECM secretion of cultured primary human PSC in vitro, a co-culture system with PBMC in the upper chamber and PSC in the lower chamber was used. Cytotoxicity and immunological incompatibilities were excluded due to spatial distance between the cells in the co-culture chambers. Here, PBMC derived from healthy donors led to a $71 \%$ increase in PSC fibronectin levels after 24 hours of co-incubation (Figure 4B). Using CP PBMC, this effect was more pronounced, with a $126 \%$ increase in fibronectin, whereas in septic shock PBMC there was a $104 \%$ increase (Figure 4B). To assess whether these effects were dependent on TGFbeta, its levels in cell culture supernatants were analyzed by ELISA. These experiments revealed significantly increased TGFbeta levels (by 130\%, 185\% and 204\%, respectively) following coculture with donor, $\mathrm{CP}$ and sepsis PBMC (Figure $4 \mathrm{~A} ; \mathrm{p}<0.0001, \mathrm{p}=0.0002$ and $\mathrm{p}=0.0004$, respectively).

\section{Coculture of PSC and PBMC induces cytokine secretion}

To determine the potential of PSC and PBMC in coculture to produce cytokines and chemokines, IL- 6 and MCP-1 levels were determined in cell culture supernatants (Figure $4 \mathrm{~A})$. Following coculture with donor, $\mathrm{CP}$ and sepsis 
A

collagen 1 , supernatants

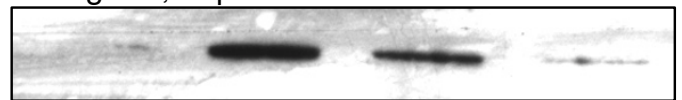

fibronectin, supernatants

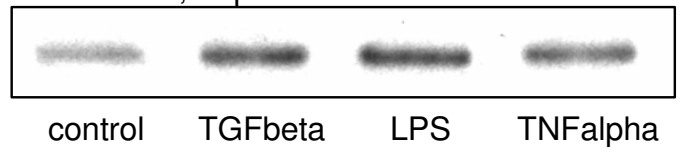

B

gamma-tubulin, cell lysates
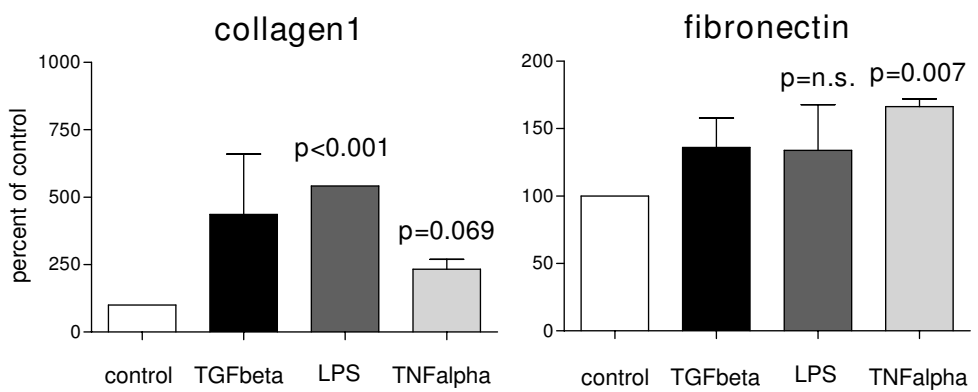

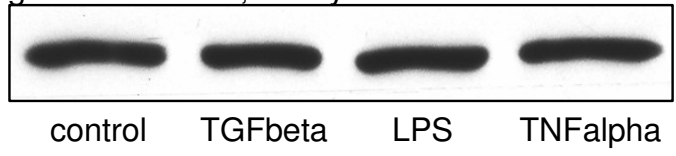

Figure 3

Immunoblot of PSC cell culture supernatants and cell lysates. Cell culture supernatants and cell lysates of vehicle-, TGFbeta-, LPS- and TNFalpha-treated PSC were subjected to SDS-PAGE followed by incubation with (A; supernatants) anticollagen I and anti-fibronectin antibodies or (B; cell lysates) an anti-gamma-tubulin antibody Densitometry is shown in percent of vehicle-treated control PSC supernatants; $n$.s. = statistically not significant.

PBMC, a significant increase of IL-6 levels in cell culture supernatants was observed (by 553\%, 531\% and $124 \%$, with $\mathrm{p}<0.0001, \mathrm{p}<0.0001$ and $\mathrm{p}=0.007$, respectively). A similar effect was seen for MCP-1, with significant induction following coculture with donor $(390 \%$ increase) and CP (370\% increase) PBMC (Figure 4A; both $\mathrm{p}<0.0001)$. However, coculture of PBMC derived from sepsis patients with PSC did not alter IL-6 levels (Figure $4 \mathrm{~A} ; \mathrm{p}=0.1$ ).

\section{Both PBMC and PSC contribute to increased cytokine levels}

Cytokine and chemokine mRNA expression levels were subsequently evaluated in PBMC and PSC to determine the source of increased cytokine/chemokine levels in cell culture supernatants. Altogether, there was an increase in cytokine mRNA expression which was more pronounced in PSC than in PBMC (Figures 5 \&6). Analysis of PBMC mRNA expression confirmed the results of the ELISA readouts. Coculture increased IL-6 expression in donor PBMC by $400 \%$ (Figure 5; $\mathrm{p}=0.005$ ), whereas for CP PBMC there was only a trend towards increased IL-6 levels following coculture (Figure 5; $\mathrm{p}=0.186$ ). In contrast to ELISA results, sepsis PBMC did not increase IL- 6 at the mRNA level. MCP-1 expression was induced by PBMC coculture with donor, $\mathrm{CP}$ and sepsis PBMC (Figure 5; $\mathrm{p}=$ $0.0003, \mathrm{p}=0.006$ and $\mathrm{p}=0.016$, respectively). Following coculture with donor and CP PBMC, expression levels of IL-6, MCP-1 and IL-8 were increased in PSC (Figure 6A; all $\mathrm{p}<0.05)$. However, sepsis PBMC did not induce cytokine
mRNA expression significantly, although a trend toward an increase was seen (Figure 5A; all p > 0.05).

\section{Increased ECM protein secretion is not accompanied by increased transcription}

A potential influence of late changes in mRNA transcription (24 hours) on the increase of ECM proteins in coculture and the contributing source of these proteins (PSC and/or PBMC) was examined using quantitative RT-PCR. Low-level expression of collagen 1 and fibronectin was unaltered in PBMC following coculture (data not shown). TGFbeta expression in PBMC was also unchanged after coculture (Figure 5; $\mathrm{p}=0.988, \mathrm{p}=0.3$ and $\mathrm{p}=0.214$, respectively). Analysis of collagen 1 and fibronectin mRNA in control and cocultured PSC revealed no changes in expression levels (Figure 6B). Furthermore, TGFbeta expression also remained unchanged after coculture (Figure 6A). Thus, the effect of coculture on ECM protein production seems to be rather independent of the transcription of the respective mRNA moieties, but may involve changes in protein processing/sorting or protein secretion.

\section{NFkappaB is not involved in signal transduction induced by coculture}

NFkappaB levels in the nuclear fraction of PSC and PBMC were determined after two hours of coculture to evaluate potential rapid effects on the transcriptional level. However, there was no difference in NFkappaB transactivation when comparing PBMC and PSC alone with cells in coculture (data not shown). 

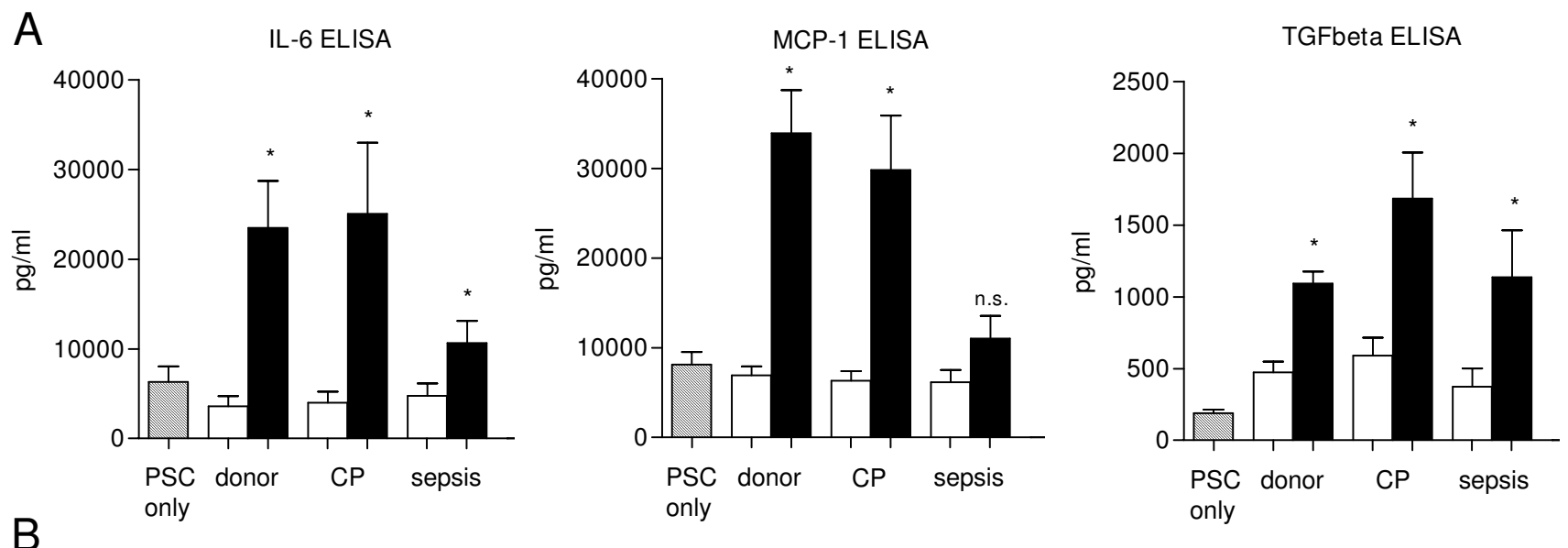

PSC coculture

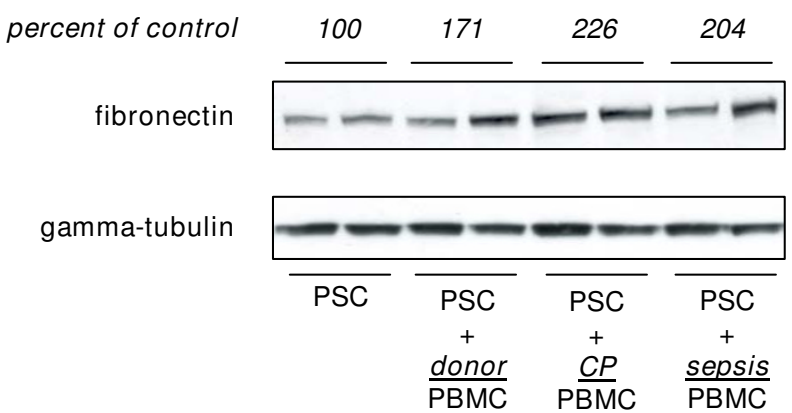

Figure 4

Analysis of PSC supernatants and cell lysates following coculture with PBMC. (A) PSC cell culture supernatants were subjected to ELISA following coculture with donor, CP and sepsis PBMC. Hatched bars: PSC supernatants. White bars: Pooled donor, CP or sepsis PBMC and corresponding PSC supernatants. Black bars: coculture supernatants. $*_{p}<0.05$ as assessed using the Mann-Whitney $U$ test. (B) Immunoblot analysis of fibronectin in PSC cell lysates. Densitometry shown as percent of control adjusted to the corresponding gamma-tubulin density.

\section{Discussion}

An important finding of this study is that PBMC-derived substances alter the phenotype of PSC towards a more pro-fibrogenic and pro-inflammatory cell-like phenotype and away from the typical myofibroblast phenotype. This assumption is underlined by increased ECM protein secretion in TNFalpha- and LPS-treated PSC and a concomitant increase in collagen 1 and fibronectin as well as in proinflammatory cytokines IL- 6 and MCP-1 following coculture of PSC with PBMC.

Progression of fibrosis in chronic pancreatitis is accompanied by inflammation and a severe pain syndrome which represents a major clinical challenge [1,9,32,33]. Recently, stellate cells themselves have emerged as inflammatory effectors $[34,35]$. Upon activation, they release a wide variety of chemokines and cytokines and upregulate the expression of key inflammatory markers $[32,36,37]$.
Since mononuclear cell infiltration is a feature shared by a variety of fibrotic diseases, increasing attention is being paid to investigating the role of immune cells in regulation of stellate cell activity $[38,39]$. Potential activators of PSC include factors such as cytokines and growth factors [40]. Activated PSC, in turn, produce autocrine factors such as periostin and TGF- $\beta$ which perpetuate their activation [28].

In our study, immunohistochemical analyses showed an influence of mononuclear cell infiltrates on PSC: There was a strong deposition of ECM proteins around the clusters of immune cells and in areas where immune cells were scarcely distributed in the stroma. On the contrary, within the packed immune clusters, there was weak (fibrononectin) or almost absent (collagen 1, alphaSMA) immunopositivity. These observations might contradict our in vitro data but could also be explained by increased 


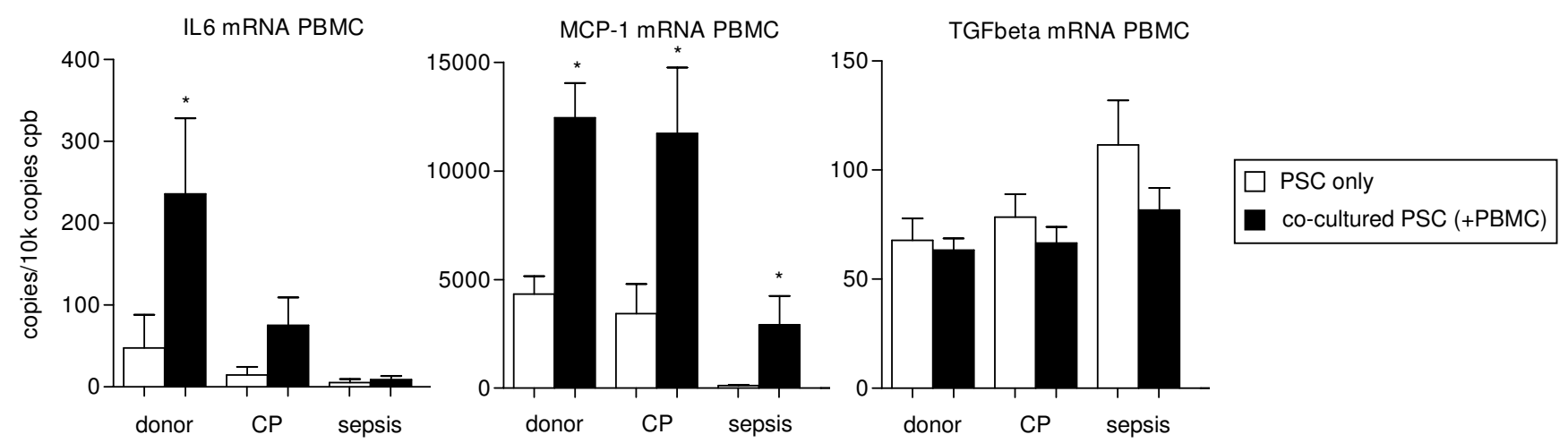

\section{Figure 5}

Messenger-RNA expression levels in single-cell and cocultured PBMC. PSC alone (without PSC; white bars) and cocultured (with PSC; black bars) PBMC were analyzed by quantitative RT-PCR using primers for IL-6, MCP-I and TGFbeta. Results are expressed as copies per $10 \mathrm{k}$ copies of cyclophilin $B(c p b)$. ${ }^{*} p<0.05$ as assessed using the Mann-Whitney $U$ test.
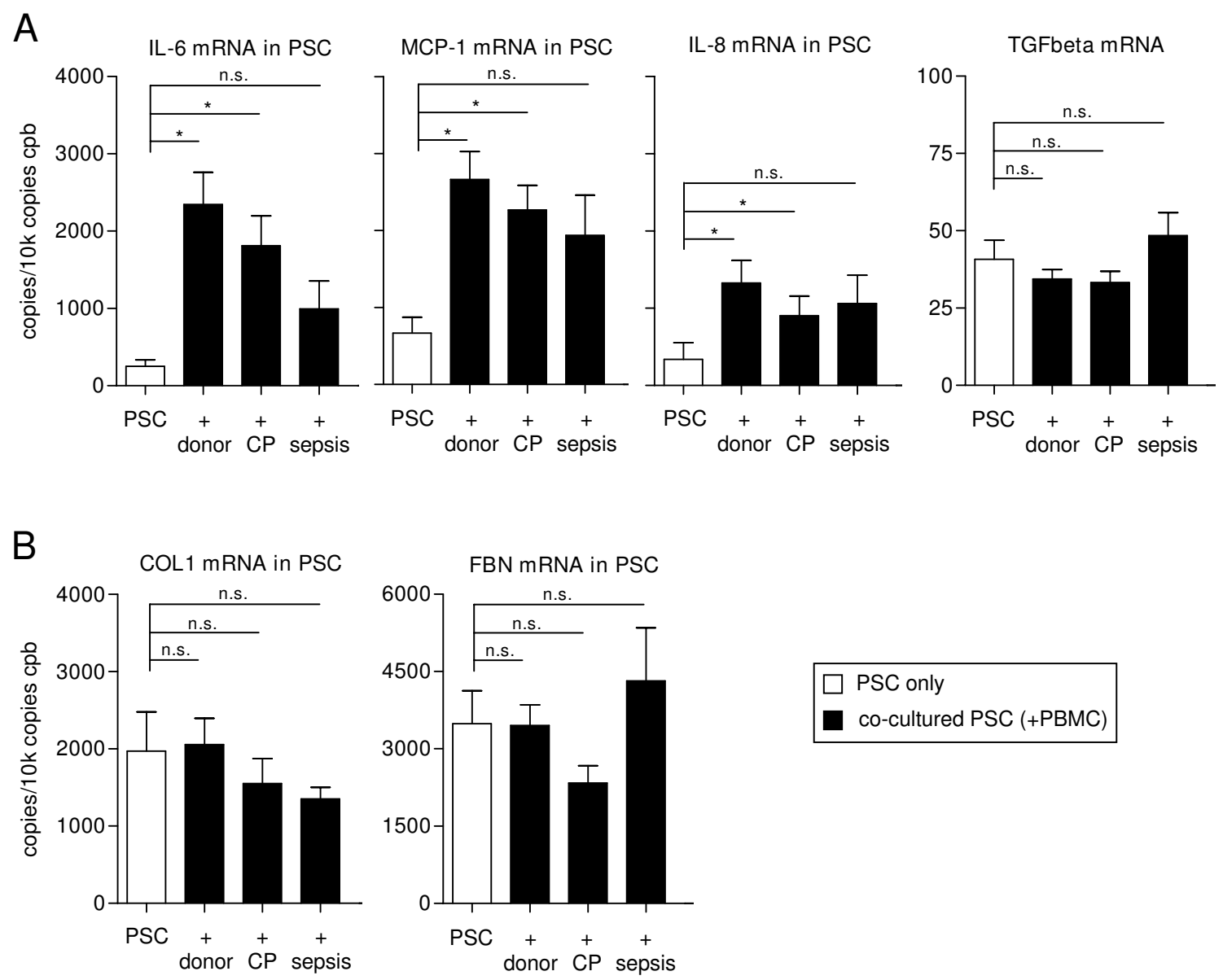

PSC only
co-cultured PSC (+PBMC)

Figure 6

Messenger-RNA expression levels in single-cell and cocultured PSC. PSC alone (without PBMC; white bars) and cocultured (with PBMC; black bars) PSC were analyzed by quantitative RT-PCR using primers for IL-6, MCP-I, IL-8 and TGFbeta (A) as well as for collagen I and fibronectin (B). Results are expressed as copies per $10 \mathrm{k}$ copies of cyclophilin B (cpb). *p < 0.05 as assessed using the Kruskal-Wallis test followed by Dunn's post-hoc test to compare single-cell PSC with cocultured PSC. 
matrix "turnover" activity and a change in PSC phenotype. Moreover, this site specific variance in ECM deposition can be due to the following reasons: 1) The packed immune clusters are actually forming in expanded perivascular spaces as hinted by the presence of central CD31 positive endothelial cells; 2) In vitro, the matrix degradation enzyme MMP-1 was increased together with an increase in ECM proteins collagen1 and fibronectin; 3) High amounts of TNFalpha exert cytotoxic effects on PSC [20] which is probably represented in vivo as a function of their density. Using immunohistochemistry, different phases of immune reaction in the pancreas were seen: in scarred areas where ECM has replaced parenchymal cells, there was also a decline in alphaSMA-positive cells whereas a large number of activated PSC were seen around injured acini and remaining ducts. We have previously shown that periostin, which sustains stellate cell activity, is mostly secreted by PSC around degenerating acini/tubular complexes [28], possibly marking the invasive front of the activated stroma where newly deposited ECM gradually replaces the functional parenchyma. These results are compatible with recent reports which observed that at the end of tissue repair, the reconstructed ECM takes over the mechanical load and myofibroblasts disappear by induction of apoptosis [41]. Our current results underline the change in PSC phenotype towards a more fibroblast-like cell type with immunologic function.

Recently, it has also been shown for hepatic stellate cells that natural killer cells and CD4 T cells may induce antifibrosis, whereas CD8 cells are rather pro-fibrotic [42]. Furthermore, cell-to-cell contact of stellate and immune cells seems ultimately not to be necessary to induce such effects, since the results of our coculture set-up point out the importance of secreted mediators. However, our findings may also be due to several other factors: first, we used PBMC, which have only been in direct contact with the inflamed pancreas to a very minor extent; second, upregulation of PSC-produced ECM proteins seems to be a function of PBMC in general, not particularly of PBMC which are derived from CP patients; and third, our study addresses interactions of PBMC and PSC in an artificial set-up which may reflect the experimental processing of both PSC and PBMC. Particularly, while there was a tendency towards an increase in fibronectin production following PSC co-culture with CP and septic shock PBMC, this increase could also have been due to activation of PSC under culture conditions (plastic cell culture dishes which lead to activation of PSC).

In terms of cytokine upregulation by PBMC, coculture seems to be a valid model: it shows that the capacity of PSC to secrete cytokines may be further increased and may thus contribute to the ongoing inflammation in chronic pancreatitis. Interestingly, PBMC derived from septic shock patients lost the ability to induce PSC cytokine expression and secretion which may be due to several reasons. It has been reported that there is a general paralysis of the immune system in sepsis [43-45]. It also seems possible that - due to the strong acute inflammation in sepsis patients - the PBMC activity state has been suppressed. Thus, the secreted mediators which induce PSC activity may be suppressed in this state. There is also an inverse regulation of IL- 6 and MCP-1 mRNA induction by PBMC derived from different sources: while the increase in IL-6 expression on the mRNA level was only seen in PBMC from healthy donors, MCP-1 was significantly induced in cocultured PBMC from donors, CP and septic shock patients. The levels of the respective proteins in the supernatants did not reflect the mRNA regulation, which may be due to accumulation in the coculture set-up and the fact that the levels in the supernatants are a result of contributions by both PBMC and PSC.

In conclusion, our study underlines that an interaction between mononuclear cells and pancreatic stellate cells may contribute to the vicious cycle of inflammation and uncontrolled scarring in chronic pancreatitis.

\section{Competing interests}

The author(s) declare that they have no competing interests.

\section{Authors' contributions}

CWM, AG and ME designed the study, carried out the experiments, analyzed the data and participated in drafting the manuscript. CR and SD participated in the immunohistochemical analyses and the immunoblot experiments. FB participated in the immunohistochemical analyses and histopathological classification of the tissues. TG carried out the quantitative RT-PCR and participated in analyzing the data. BS, HF and NAG conceived of the study, participated in its design and coordination. JK conceived of the study, participated in its coordination and helped to draft the manuscript. All authors read and approved the final manuscript.

\section{Acknowledgements}

We thank Brunhilde Bentzinger, Monika Meinhardt and Kathrin Schneider for excellent technical support. This study was supported by a postdoctoral research grant from Heidelberg University (to CWM) and by a grant from the Deutsche Forschungsgemeinschaft (SEI095, to CWM).

\section{References}

I. Di Sebastiano P, di Mola FF, Buchler MW, Friess H: Pathogenesis of pain in chronic pancreatitis. Dig Dis 2004, 22(3):267-272.

2. DiMagno MJ, DiMagno EP: Chronic pancreatitis. Curr Opin Gastroenterol 2005, 2 I (5):544-554.

3. Friess $\mathrm{H}$, Kleeff $\mathrm{J}$, Buchler MW: Molecular pathophysiology of chronic pancreatitis--an update. J Gastrointest Surg 2003, 7(8):943-945.

4. Schmid RM, Adler G: Chronic pancreatitis. N Engl J Med 1995, 333( I 8): 1222. 
5. Whitcomb DC: Mechanisms of disease: Advances in understanding the mechanisms leading to chronic pancreatitis. Nat Clin Pract Gastroenterol Hepatol 2004, I(I):46-52.

6. Bockman DE, Buchler M, Malfertheiner P, Beger HG: Analysis of nerves in chronic pancreatitis. Gastroenterology 1988, 94(6): 1459- | 469.

7. Apte MV, Haber PS, Applegate TL, Norton ID, McCaughan GW Korsten MA, Pirola RC, Wilson JS: Periacinar stellate shaped cells in rat pancreas: identification, isolation, and culture. Gut I998, 43(I): I28-133.

8. Bachem MG, Schneider E, Gross H, Weidenbach H, Schmid RM, Menke A, Siech M, Beger H, Grunert A, Adler G: Identification, culture, and characterization of pancreatic stellate cells in rats and humans. Gastroenterology 1998, I I5(2):42 I-432.

9. Apte MV, Wilson JS: Mechanisms of pancreatic fibrosis. Dig Dis 2004, 22(3):273-279.

10. Jaster R: Molecular regulation of pancreatic stellate cell function. Mol Cancer 2004, 3:26.

II. Kloppel G, Detlefsen S, Feyerabend B: Fibrosis of the pancreas: the initial tissue damage and the resulting pattern. Virchows Arch 2004, 445(I): I-8.

12. Imamura M, Ogawa T, Sasaguri $Y$, Chayama K, Ueno H: Suppression of macrophage infiltration inhibits activation of hepatic stellate cells and liver fibrogenesis in rats. Gastroenterology 2005, I 28(I): $138-146$

13. Ramadori G, Saile B: Inflammation, damage repair, immune cells, and liver fibrosis: specific or nonspecific, this is the question. Gastroenterology 2004, I 27(3):997-1000.

14. Safadi R, Ohta M, Alvarez CE, Fiel MI, Bansal M, Mehal WZ, Friedman SL: Immune stimulation of hepatic fibrogenesis by CD8 cells and attenuation by transgenic interleukin- 10 from hepatocytes. Gastroenterology 2004, I 27(3):870-882.

15. Heinzel FP, Sadick MD, Holaday BJ, Coffman RL, Locksley RM: Reciprocal expression of interferon gamma or interleukin 4 during the resolution or progression of murine leishmaniasis. Evidence for expansion of distinct helper $\mathbf{T}$ cell subsets. J Exp Med 1989, I69(I):59-72.

16. Shi Z, Wakil AE, Rockey DC: Strain-specific differences in mouse hepatic wound healing are mediated by divergent $T$ helper cytokine responses. Proc Natl Acad Sci U S A 1997, 94(20): 10663-10668.

17. Iredale JP, Benyon RC, Pickering J, McCullen M, Northrop M, Pawley S, Hovell C, Arthur MJ: Mechanisms of spontaneous resolution of rat liver fibrosis. Hepatic stellate cell apoptosis and reduced hepatic expression of metalloproteinase inhibitors. J Clin Invest 1998, I 02(3):538-549.

18. Song E, Ouyang N, Horbelt M, Antus B, Wang M, Exton MS: Influence of alternatively and classically activated macrophages on fibrogenic activities of human fibroblasts. Cell Immunol 2000, 204(I): 19-28

19. Mariani TJ, Sandefur S, Roby JD, Pierce RA: Collagenase-3 induction in rat lung fibroblasts requires the combined effects of tumor necrosis factor-alpha and I2-lipoxygenase metabolites: a model of macrophage-induced, fibroblast-driven extracellular matrix remodeling during inflammatory lung injury. Mol Biol Cell 1998, 9(6): I4I I-I424.

20. Hanck C, Rossol S, Hartmann A, Singer MV: Cytokine gene expression in peripheral blood mononuclear cells reflects a systemic immune response in alcoholic chronic pancreatitis. Int J Pancreatol I999, 26(3): I37-I 45.

21. Schmid-Kotsas A, Gross H], Menke A, Weidenbach H, Adler G, Siech M, Beger H, Grunert A, Bachem MG: Lipopolysaccharide-activated macrophages stimulate the synthesis of collagen type I and C-fibronectin in cultured pancreatic stellate cells. Am J Pathol 1999, I55(5): 1749-1758.

22. Apte MV, Haber PS, Darby SJ, Rodgers SC, McCaughan GW, Korsten MA, Pirola RC, Wilson JS: Pancreatic stellate cells are activated by proinflammatory cytokines: implications for pancreatic fibrogenesis. Gut 1999, 44(4):534-54I.

23. Shek FW, Benyon RC, Walker FM, McCrudden PR, Pender SL, Williams EJ, Johnson PA, Johnson CD, Bateman AC, Fine DR, Iredale JP: Expression of transforming growth factor-beta I by pancreatic stellate cells and its implications for matrix secretion and turnover in chronic pancreatitis. Am J Pathol 2002, 160(5): I $787-1798$.
24. Hellerbrand $C$, Jobin $C$, limuro $Y$, Licato L, Sartor RB, Brenner DA: Inhibition of NFkappaB in activated rat hepatic stellate cells by proteasome inhibitors and an IkappaB super-repressor. Hepatology I998, 27(5): | 285- I 295.

25. Berenguer M, Ferrell L, Watson J, Prieto M, Kim M, Rayon M, Cordoba J, Herola A, Ascher N, Mir J, Berenguer J, Wright TL: HCV. related fibrosis progression following liver transplantation: increase in recent years. J Hepatol 2000, 32(4):673-684.

26. Soto B, Sanchez-Quijano A, Rodrigo L, del Olmo JA, Garcia-Bengoechea M, Hernandez-Quero J, Rey C, Abad MA, Rodriguez M, Sales Gilabert M, Gonzalez F, Miron P, Caruz A, Relimpio F, Torronteras R, Leal $M$, Lissen $E$ : Human immunodeficiency virus infection modifies the natural history of chronic parenterally-acquired hepatitis $\mathbf{C}$ with an unusually rapid progression to cirrhosis. J Hepatol 1997, 26(I): I-5.

27. Lotersztajn S, Julien B, Teixeira-Clerc F, Grenard P, Mallat A: Hepatic fibrosis: molecular mechanisms and drug targets. Annu Rev Pharmacol Toxicol 2005, 45:605-628.

28. Erkan M, Kleeff J, Gorbachevski A, Reiser C, Mitkus T, Esposito I, Giese T, Buchler MW, Giese NA, Friess H: Periostin Creates a Tumor-Supportive Microenvironment in the Pancreas by Sustaining Fibrogenic Stellate Cell Activity. Gastroenterology 2007, 132(4): |447-| 464.

29. Michalski CW, Laukert T, Sauliunaite D, Pacher P, Bergmann F, Agarwal N, Su Y, Giese T, Giese NA, Batkai S, Friess H, Kuner R: Cannabinoids ameliorate pain and reduce disease pathology in caerulein-induced acute pancreatitis. Gastroenterology 2007, I32(5): 1968-78.

30. Martignoni ME, Kunze P, Hildebrandt W, Kunzli B, Berberat P, Giese T, Kloters O, Hammer J, Buchler MW, Giese NA, Friess H: Role of mononuclear cells and inflammatory cytokines in pancreatic cancer-related cachexia. Clin Cancer Res 2005, I I ( I 6):5802-5808.

31. Erkan M, Kleeff J, Esposito I, Giese T, Ketterer K, Buchler MW, Giese NA, Friess H: Loss of BNIP3 expression is a late event in pancreatic cancer contributing to chemoresistance and worsened prognosis. Oncogene 2005, 24(27):442I-4432.

32. Andoh A, Takaya H, Saotome T, Shimada M, Hata K, Araki $Y$, Nakamura $F$, Shintani $Y$, Fujiyama $Y$, Bamba $T$ : Cytokine regulation of chemokine (IL-8, MCP-I, and RANTES) gene expression in human pancreatic periacinar myofibroblasts. Gastroenterology 2000, II9(I):21|-219.

33. DiMagno MJ, DiMagno EP: Chronic pancreatitis. Curr Opin Gastroenterol 2004, 20(5):444-45।.

34. Marra F: Chemokines in liver inflammation and fibrosis. Front Biosci 2002, 7:d 899-9|4.

35. Schwabe RF, Bataller R, Brenner DA: Human hepatic stellate cells express CCR5 and RANTES to induce proliferation and migration. Am J Physiol Gastrointest Liver Physiol 2003, 285(5):G949-58.

36. Azouz A, Razzaque MS, El-Hallak M, Taguchi T: Immunoinflammatory responses and fibrogenesis. Med Electron Microsc 2004, 37(3): $|4|-\mid 48$.

37. Detlefsen S, Sipos B, Feyerabend B, Kloppel G: Fibrogenesis in alcoholic chronic pancreatitis: the role of tissue necrosis, macrophages, myofibroblasts and cytokines. Mod Pathol 2006, 19(8): 1019-1026.

38. Kobayashi S, Seki S, Kawada N, Morikawa H, Nakatani K, Uyama N, Ikeda K, Nakajima Y, Arakawa T, Kaneda K: Apoptosis of T cells in the hepatic fibrotic tissue of the rat: a possible inducing role of hepatic myofibroblast-like cells. Cell Tissue Res 2003, 3I I (3):353-364.

39. Sparmann G, Glass A, Brock P, Jaster R, Koczan D, Thiesen HJ, Liebe $S$, Emmrich J: Inhibition of lymphocyte apoptosis by pancreatic stellate cells: impact of interleukin- 15. Am J Physiol Gastrointest Liver Physiol 2005, 289(5):G842-5I.

40. Omary MB, Lugea A, Lowe AW, Pandol S): The pancreatic stellate cell: a star on the rise in pancreatic diseases. J Clin Invest 2007, I I 7(I):50-59.

4I. Carlson MA, Longaker MT, Thompson JS: Wound splinting regulates granulation tissue survival. J Surg Res 2003, I I 0(I):304-309.

42. Muhanna N, Horani A, Doron S, Safadi R: Lymphocyte-hepatic stellate cell proximity suggests a direct interaction. Clin Exp Immunol 2007, I 48(2):338-347. 
43. Heumann $D$, Glauser MP, Calandra T: Monocyte deactivation in septic shock. Curr Opin Infect Dis 1998, I I (3):279-283.

44. Wesche DE, Lomas-Neira JL, Perl M, Chung CS, Ayala A: Leukocyte apoptosis and its significance in sepsis and shock. J Leukoc Biol 2005, 78(2):325-337.

45. Fujihara M, Muroi M, Tanamoto $\mathrm{K}$, Suzuki $\mathrm{T}$, Azuma $\mathrm{H}$, lkeda $\mathrm{H}$ : Molecular mechanisms of macrophage activation and deactivation by lipopolysaccharide: roles of the receptor complex. Pharmacol Ther 2003, 100(2):17I-194.

Publish with Bio Med Central and every scientist can read your work free of charge

"BioMed Central will be the most significant development for disseminating the results of biomedical research in our lifetime. " Sir Paul Nurse, Cancer Research UK

Your research papers will be:

- available free of charge to the entire biomedical community

- peer reviewed and published immediately upon acceptance

- cited in PubMed and archived on PubMed Central

- yours - you keep the copyright

Submit your manuscript here:

http://www.biomedcentral.com/info/publishing_adv.asp
BioMedcentral 